\title{
The Impact of Environmental-organizational Factors on the Commercialization of Scientific Research Results in the Branches of Lorestan Islamic Azad University
}

\author{
Mansour Torkiantabar \\ Department of Management, Islamic Azad University, Dorood branch, Dorood, Iran \\ Corresponding Author. Email: Torkiantabar@yahoo.com \\ Mohammad Reza Hashemi \\ Department of Management, Islamic Azad University, Dorood branch, Dorood, Iran \\ Email: hashemi@iau-doroud.ac.ir
}

\author{
Doi:10.5901/mjss.2015.v6n6s6p326
}

\section{Abstract}

\begin{abstract}
The current article intends to shed light on the impact of organizational and environmental factors on the commercialization of academic research results from the viewpoint of faculty members practicing in the four branches of Lorestan Islamic Azad University (Aligudarz, Borujerd, Khorramabad, Dorud) by a descriptive-survey methodology. The study statistical population is composed of 525 members of the faculty of the relevant branches, which of them, 222 members were selected as sample by using Cochran formula, and questionnaires were randomly divided between them. After the questionnaires were distributed, 177 completed questionnaires were received, and the data of the same number of questionnaire were analyzed using SPSS software. The research results showed that from the viewpoint of the faculty members of the four branches of Lorestan Islamic Azad University, the availability of technological tools out of university with an average of 3.75, interest and pursuing of research managers with an average of 3.48 and availability of technological tools within university with an average of 3.41 have the greatest impact on the commercialization of scientific research results. On the other hand, from the faculty members' perspective, creating a database of researchers by universities with an average of 2.43 , the presence and activities of technology parks in the surrounding area with an average of 2.72 and faculty members' access to knowledgeable consultants with an average of 2.75 have the least impact on this area.
\end{abstract}

\section{Introduction}

Development of specific strategies for technology transfer is closely associated with investment and business partnership with higher education. Many countries regard their future economic welfare as an issue dependent on taking advantage of the discoveries and technological achievements and prompt usage of them in the manufacturing process. What appears to be a relatively irregular process and represents itself through discoveries in the academic laboratory, ultimately finds its own way to commercial production, and will play effective roles through policy making and generation of institutional and individual revenue by academic individuals and groups (Khorshidi, 2004, 192).

Knowledge-based economy is the result of a more complete understanding of the role played by knowledge in economic growth. With the advancement of knowledge, knowledge-based economy has become dependent upon production, distribution and use of knowledge with more intensity, and production and employment in the industry have grown more rapidly. Also, knowledge-based services including training and technical communications are nowadays growing more rapidly. According to available evidence, the leading countries in the knowledge-based economy are in a transition from an industrial economy to a knowledge-based post-industrial economy, and growth and productivity is considerably the consequence of technical progress and the accumulation of knowledge (Memarnezhad, 2005, 91- 92).

University's policy makers should pay special attention to the role and high position of faculty members in the commercialization process. Also, providing the necessary support to publish articles in scientific journals and attending valid conferences are of special significance to increase members' impact factor on the uptake and adoption of industry research needs. This causes universities to push a part of their research policy toward market needs' based on the capacity of human resources and facilities (applied and development research) and thereby increase the availability of non-governmental sources of revenue (Hashemnia. et al., 2009, 17).

Universities and higher education institutions, in terms of their critical mission, play an important role in education and research. From one side, they train skilled manpower for labor market and on the other side, they generate 
knowledge, which the latter has been doubly vital in the current global conditions. This means that knowledge production has an additional value when it can be converted into goods and services and become useful and valuable for the international community. Identify the factors influencing the commercialization of results of academic research in universities and educational institutions of Iran can significantly contribute to recognize strengths and weaknesses of universities in this area. Therefore, such identification plays an important role in providing a fertile ground for commercialization of academic products. In addition, faculty members which are directly associated with the category of science production, more than any other group in society, are informed of the challenges and issues facing the commercialization of scientific research results, and from their perspective, knowledge and understanding are is of the utmost significance in this process.

\section{Problem Statement}

Commercialization of science and technology has a long history. Although, in the past, academic research was utilized to generate and develop knowledge and technologies, rarely these technologies were introduced in the market or commercialized. It seems that the commercialization of science and technology began with the presentation of some arguments on the establishment of collaboration between universities and industry, concurrent with the Morrill Act of 1862 based on which universities were endowed with the right to own land. This cooperation has a long history. For example, the United States Department of Defense regarded cooperation and partnerships between development and research departments of universities as the main source of progress during the Second World War, and the era of competition with the Soviet Union. Although this critical issue was apparently not conspicuous, it was the interaction between academia and industry that significantly contributed to the processes and results of research and technology (Markman et al., 2008).

In the knowledge-based economy, in addition to education and research mission, universities have been involved in their third mission which is further participation in the process of innovation and technological development. Accordingly, new networks affiliated to universities are growing, and the universities with regard to their capacity as the producer and distributor of knowledge and also entrepreneurial institutions, play a fundamental role in industrial innovation and technology development. Consequently, such approach underlying educational and training activities is a demand oriented approach and more inclined toward university's external organizations (Baqerinejad, 2001, 369).

The universities play an infrastructure role in economic development. Shortcomings of human resources, both in terms of numbers and in terms of type and quality, are one of the most fundamental constraints to economic development. Furthermore, the development of education, especially academic education development requires financial and material resources, and as the financial and material resources are the product of economic development, one of the major problems and bottlenecks of developing countries in terms of education in general, and university development in particular is such countries inability's to afford the relevant high costs. Accordingly, economic development and the development of academic trainings are mutually reactive and interdependent (Faiouzat, 2003, 20).

Commercialization of the results of academic research as a key factor in economic growth and development is important for all countries, which Iran is no exception. Using commercialization, the different countries in the world intend to not only pay special attention to entrepreneurship, but also provide fertile grounds for employment creation and consequently the social welfare of citizens. In the process of commercialization of scientific research results, several factors are involved that their knowledge can be effective in removing commercialization barriers. A set of such factors are organizational-behavioral ones which can include access to knowledgeable consultants, interest shown by research directors, creating a database of experts by the university, helping to enhance the ability of faculty members, etc. Thus, the present study aims to answer the questions that: according to the faculty members of the departments of Islamic Azad University in Lorestan Province, organizational and environmental factors to what extent can influence the commercialization of scientific research results.

\section{Research Literature}

Wolf believes that universities are operating in a knowledge-based economy, and their role is not either confined to traditional roles and conduct basic research. Many policy makers consider research universities as "knowledge factories" for the new economy with resources from commercializible knowledge that are waiting to be applied by firms. He also believes that, in nowadays' universities, education means creating new competencies and capabilities and gain new skills rather than mere access to information and scientific knowledge. Successful education leads to interaction and also support from companies and institutions in a specific region (Wolf, 2005). 
University is a social institution and has a history of about eight hundred years old. This institution, in its early stages, only paid attention to educational activities for a long time (Duncan and others, 1998). However, based on university's internal dynamics and the external effects on academic and scientific structures, two scientific revolutions have been occurred. The first revolution is academic and scientific development occurred at German universities in the late nineteenth century during which the universities in addition to education and teaching, used to undertake the responsibility of a research mission as well. The second scientific revolution, based on the reliance of innovations on scientific knowledge, occurred in the late twentieth century, during which university in addition to educational and research mission undertook a third mission which was technological innovation. Today, universities that have a third mission are called entrepreneurial universities (Saljughi, 2006, 54).

Dovani and Herder (2007) in an article entitled "Insights about the commercialization of the research carried out in the public institutions of Canada" wrote that a new office has been created in universities. Nowadays, many universities have some sectors such as Department of Business Development, Technology Transfer Office or some other instances with a similar name to commercialize the research results of the institutions and companies. Members of these offices include business sector managers and the lawyers specializing in contracts.

Barton Clarke believes that the dynamic universities in the twenty-first century are entrepreneurial universities that are able to merge the specialized and managerial values. In our time, the training focused on entrepreneurship at universities in developed and developing countries is increasing. Such programs have been designed to create scientific experiments and processes suitable for the production of new goods. These types of programs normally help students to generate new ideas and to implement these ideas by using pre-planned strategies. In these programs, different educational methods are applied to improve students' skills to enter the labor market and establish commercial firms (Saeedikia, 2007, 12).

It is possible to generate innovative ideas in universities and research institutions in the form of research projects, which definitively leads to scientific progress. However, push these developments toward the industry, compensate the lack of investment for production, offer them in the form of a product to market and ultimately create economic value from scientific research are some of the important steps about which governments can play an important role (Krupp and Zolin 2005). Knowledge generated by the university will not be transferred automatically to the commercial realm, and the main carriers of this knowledge in the early stages of commercialization are educated people that are directly involved in its actual production. The high level of tacit knowledge inspired from the creation of a research-based business idea often suggest that these new views initially are formed in the minds of people subjectively (Hyndel and Yinken 2004).

In fact, the broader interpretation of the thesis namely "knowledge corridor" may be more useful in academic environments, as it was proven that work experience and activity in the private sector of the business environment can affect the ability to attract opportunities to commercialize research (Lubango and Porys 2007).

In recent decades, mission, goals and programs of universities have undergone significant changes. In the past, universities were only responsible for the training, but the first changes in their system began since the late nineteenth century, and research was also added to the functions of universities (Etzkowitz, 2003). Some experts believe that the main cause of the inefficiency of the Iran's higher education system is the weakness of its research structure, and they believe that the process of achieving data research primarily requires a long time, and as governments and people in the third world do not have the patience for such a long time due to budget shortage, class chasms and poverty and try to solve crisis in the short-term, thus the structure of the research in this type of systems cannot be institutionalized (Nobakht, 2008, 68).

The countries that have taken basic steps in development and achieved necessary technologies believe that ability to keep pace with and also surpass others depends on innovation skill for achieving development, and it is worth mentioning that is the main source of innovation is research activities. Hence these countries regard establishment of research institutions and investment on them as important as direct investment in development projects, and as an important factor to create an environment where technology development activities can be fulfilled. In fact, the importance of investment on research in advanced industrial countries is assumed an incontestable issue, and today this is research that determines how to allocate funds, cost and financial issues (Khorshidi, Gh., 2004, 155).

\section{Research Background}

Wright et al (2007), in their study, regarded academic entrepreneurship as a process not merely focused on universities' traditional practices, i.e. the concession of intellectual property, and stated that it is an issue including the establishment of spin-off companies through technology and knowledge generated in universities.

Houshmand et al (2004) in a study entitled "A model for evaluation of knowledge management and knowledge- 
based organization as a mission of Qom University" concluded that Qom University has not much focus on knowledge management and is in a moderate level of readiness to implement knowledge management. In addition, the results from Friedman Ranking Test suggests that enablers and sub-processes under investigation are not in a good condition, and the factors including "organizational culture" and "knowledge production" at the University of Qom have received the least attention and the factors "education" and "application of knowledge" received the highest attention (Houshmand, Mir Afzal, Rezaeinour, 2004, 65).

Ansari and Sanjabi (2013) in their study entitled "The challenges to research commercialization from the perspective of the faculty members of Iranian agricultural universities" reached the conclusion that, in the area of commercialization challenges from the perspective of faculty members, Iran has the highest rankings in terms of educational-information and infrastructure-support challenges. In addition, the results from exploratory factor analysis showed that the commercialization challenges to agricultural universities' research are overshadowed by seven distinct factors including infrastructure-support, training-communicative, technical-specialized, organizational-financial, and policy making. These factors have explained 57.40 percent of the total variance of variables (Ansari, Sanjabi, 2013, 555).

In a study entitled "Extra-organizational factors influencing the commercialization of research results", Jahed and Arasteh (2013) concluded that extra-organizational factors including government forces, economic forces, educational system, macro regulation, technological developments, competition and competitiveness and customer orientation can influence the commercialization of research results. In explaining the impact of these factors, the results showed that the most factors are significantly correlated with each other (Jahed, Arasteh, 45, 2013).

Razavi et al (2013) in their study entitled "Evaluation of outcomes and commercialization of the research designs proposed by Faculty of Pharmacy, Shahid Beheshti University of Medical Sciences (2001-2011)" stated that out of 193 research projects, 190 (98.4 percent) had files, 100\% had proposal, and 100\% had written final reports. In $80 \%$ of research designs, according to the research designs, there was possibility of applying the findings. Some of the most significant achievements of Faculty of Pharmacy include 40 drug products, a patent, 5 spin-off companies, one development center, 23 joint programs with industry, and an income of 20 billion Rials. All the above indicators in 2011 were higher than other years (Razavi, Emami, Valaei, 2013, 220).

In a study entitled "The function of research commercialization dimensions on entrepreneurial development and research in Iran's agricultural sector" by Alam Beigi and colleagues (2012), the authors concluded that in the process of entrepreneurial development and research, two factors namely value-added technology and sustainable innovation have the highest significance compared to other dimensions. Furthermore, the results of path analysis showed that among the research commercialization dimensions, two factors namely entrepreneurial considerations in the preparation and development of technology package, and specification of technology strategies and areas have the greatest impact on the formation of entrepreneurial research and development, while some factors such as drawing a roadmap and the evaluation of technology do not significantly impact such formation (Alam Begay et al., 2012, 49).

Amin Mozaffari and Shamsi (2011) in their study examined methods and approaches in the commercialization of academic research. The results showed that commercialization process in the years under study has constantly made headway. Also, regarding the identification of a link between the performance variables and how they can influence the commercialization, it was found that there is a significant relationship between the variables such as publication of papers at conferences, joint research contracts and graduate studies theses (MA) with commercialization (Amin Mozaffari, Shamsi, 2011, 15).

Given the research findings, it can be concluded that commercialization of scientific results in Iran is faced with some challenges such as a lack of awareness, lack of adequate support, and various personal, cultural, organizational issues, etc. The results show that although the issue of research in universities has been considered as worthy and necessary, the research results are not commercialized properly, and there are some obstacles to the process such as intra- or extra-organizational factors and some personal considerations.

\section{Research Methodology}

The research methodology is of a descriptive-survey type and the population includes all faculty members practicing in different branches of Loresatn Islamic Azad University including Khorramabad, Boroujerd, Doroud, and Aligoudarz, which 177 of them were randomly selected as the sample. A questionnaire was used to gather the required information. The questionnaire consisted of 46 questions, which were designed in two parts of individual and specific items. Of these, 13 questions were dedicated to the impact of environmental and organizational factors on commercialization. Upon the receipt of the questionnaires, extracted data were analyzed using SPSS software. 


\section{Research Findings}

\subsection{Demographic Characteristics}

Table 1: Respondents' gender and age

\begin{tabular}{|c|c|c|c|c|c|c|c|}
\hline \multicolumn{9}{|c|}{ Sex } \\
\hline \multicolumn{7}{|c|}{ Male } & \multicolumn{2}{c|}{ Female } & \multicolumn{3}{c|}{ Total } \\
\hline Frequency & Percent & Frequency & Percent & Frequency & Percent \\
\hline 106 & 59.9 & 71 & 40.1 & 17 & 100 \\
\hline \multicolumn{7}{|c|}{ Age } \\
\hline Less than 35 & \multicolumn{2}{|c|}{$35-54$} & $45-55$ & Over 50 Years Old \\
\hline Frequency & Percent & Frequency & Percent & Frequency & Percent & Frequency & Percent \\
\hline 38 & 21.5 & 70 & 39.5 & 47 & 26.6 & 22 & 12.4 \\
\hline
\end{tabular}

According to Table 1, out of 177 respondents, 106 (59.9\%) are male and 71 (40.1\%) female. Of this number, 38 (21.5\%) are less than 35 years old, $70(39.5 \%)$ are 35 to 45 years old, $47(26.6 \%)$ are $45-55$ years old, and $22(12.4 \%)$ are over 55 years old.

Table 2: Scientific Ranking \& Educational Group of Respondents

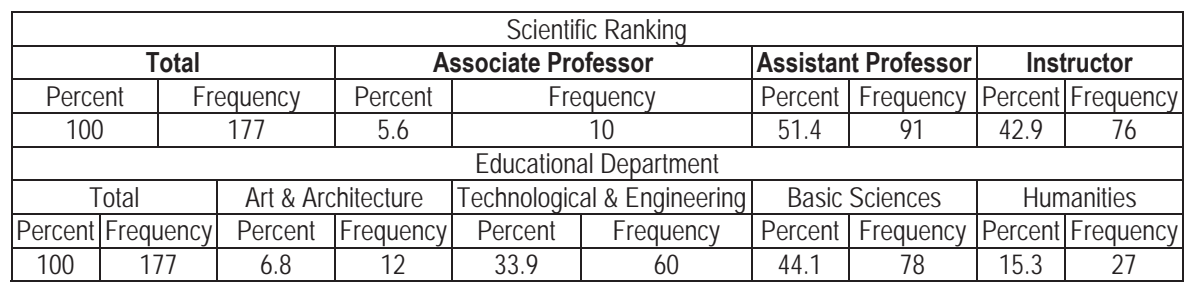

According to Table 2, 76 (42.9\%) of the respondents have the academic rank of "instructor", 91 (51.4\%) are "assistant professor", and $10(5.6 \%)$ are associate professor. Accordingly, $27(15.3 \%)$ are practicing in the department of humanities, 78 (44.1 percent) are in the department of Basic Sciences, 60 (33.9\%) in the department of technology and engineering and 12 (6.8\%) are engaged in the department of art and architecture.

Table 3: Status of responding to the questions related to organizational and environmental factors

\begin{tabular}{|c|c|c|c|c|c|c|c|c|c|c|c|c|}
\hline \multirow[b]{2}{*}{ 孞 } & & \multicolumn{2}{|c|}{ Very Much } & \multicolumn{2}{|c|}{ Much } & \multicolumn{2}{|c|}{ Fairly } & \multicolumn{2}{|c|}{ Low } & \multicolumn{2}{|c|}{ Very Low } & \multirow[b]{2}{*}{ 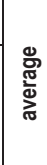 } \\
\hline & & $\begin{array}{c}\text { 즘 } \\
\text { 언 } \\
\text { 헌 }\end{array}$ & 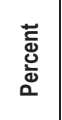 & 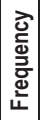 & 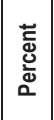 & 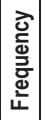 & 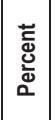 & 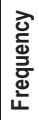 & 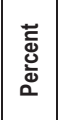 & 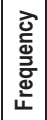 & $\begin{array}{l}\text { 픙 } \\
\text { త্ㅎํ } \\
\text { வ }\end{array}$ & \\
\hline 1 & University administrators familiarity with the processes and methods of commercialization & 21 & 11.9 & 69 & 39 & 51 & 28.8 & 33 & 18.6 & 3 & 1.7 & 3.4 \\
\hline 2 & Access of faculty members aware consultants & 13 & 7.3 & 44 & 24.9 & 31 & 17.5 & 65 & 36.7 & 24 & 13.6 & 2.75 \\
\hline 3 & Interest and pursuit of research issues by managers & 56 & 31.6 & 45 & 25.4 & 30 & 16.9 & 20 & 11.3 & 26 & 14.7 & 3.48 \\
\hline 4 & Universities' attempts to introduce and identify threats and opportunities & 44 & 24.9 & 46 & 26 & 21 & 11.9 & 35 & 19.8 & 31 & 17.5 & 3.2 \\
\hline 5 & Universities' attempts to introduce the capabilities of faculty members & 18 & 10.2 & 82 & 46.3 & 31 & 17.5 & 39 & 22 & 7 & 4 & 3.36 \\
\hline 6 & The presence and activities of technology parks in the surroundings & 15 & 8.5 & 31 & 17.5 & 48 & 27.1 & 56 & 31.6 & 27 & 15.3 & 2.72 \\
\hline 7 & The presence and activity of funds & 24 & 13.6 & 53 & 29.9 & 27 & 15.3 & 60 & 33.9 & 13 & 3.7 & 3.08 \\
\hline 8 & Information knowledge of research officials of university & 22 & 12.4 & 52 & $29 / 4$ & 65 & 31.6 & 39 & 22 & 8 & 4.5 & 3.23 \\
\hline 9 & Collaboration with the university to provide research priorities & 22 & 12.4 & 64 & 36.2 & 39 & 22 & 45 & 25.4 & 7 & 4 & 3.27 \\
\hline 10 & Create a database of researchers by universities & 8 & 4.5 & 31 & 17.5 & 25 & .114 & 79 & 44.6 & 34 & 2.19 & 2.43 \\
\hline 11 & Conferences and events to gain credibility and communication & 22 & 12.4 & 70 & 35.9 & 45 & 25.4 & 28 & 15.8 & 12 & 6.8 & 3.53 \\
\hline 12 & The availability of technological tools within university & 25 & 14.1 & 84 & 47.5 & 27 & 15.3 & 32 & 18.1 & 9 & 5.1 & 3.41 \\
\hline 13 & The availability of technological tools out of university & 58 & 32.8 & 63 & 35.6 & 20 & 11.3 & 27 & 15.3 & 9 & 5.1 & 3.75 \\
\hline
\end{tabular}

According to Table 3 below, based on the viewpoint of faculty members practicing in the branches of Lorestan Islamic 
Azad University, some factors such as availability of technological tools out of university with an average of 3.75 , interest and pursuing of research managers with an average of 3.48 and availability of technological tools within university with an average of 3.41 have the greatest impact on the commercialization of scientific research results, respectively. On the other hand, the creation of researchers' database by universities with an average of 2.43 , the presence and activities of technology parks in the surrounding area with an average of 2.72 and faculty access to knowledgeable consultants with an average of 2.75 has the least impact on this area.

Table 5: The extent of environmental-organizational impacts on research commercialization

\begin{tabular}{|l|c|c|c|c|c|c|}
\hline & Mean & St. Deviation & St. Error & T Number & D.F. & Sig. Level \\
\hline Environmental-organizational impacts on research commercialization & 3.1360 & 0.39006 & 0.02932 & 106.963 & 176 & 0.000 \\
\hline
\end{tabular}

Single-sample t-test results showed that, based on the respondents' view, the extent of the effect of environmentalorganizational factors on commercialization of research is at a high level because the mean obtained (3.13) is higher than the assumed mean (3), and also the obtained significance level is less than 0.05 .

\section{Discussion and Conclusion}

Commercialization of research results and scientific research is undeniably a key factor in the economic development of the world countries. What could be inferred from a review of the relevant resources is the fact that in today's constantly changing and evolving world where different countries are determined to overtake each other economically, importance and status of scientific research results, especially academic research is obvious more than before. Statistics show acceptable growth of knowledge in Iran. The increasing number of Iranian researchers' scientific papers published in international journals is a clear evidence of this issue. More importantly, many of these articles are the result of research activities of academic researchers that, despite the possibility of exploitation and application of their results, do not utilize these results due to some domestic limitations and challenges, and the result are actually used by other countries. What is certain is that if the results of researchers, especially academic ones, find their own way toward the commercialization, they can provide the country with valuable economic benefits and will accelerate the process of economic development. However, it seems there are some obstacles to the realization of this important issue. Economic, political, cultural, managerial, organizational, and environmental factors are among the factors that their impact on the studies carried out in the country have been approved, and the results of this study also affirms the existence of environmental and organizational barriers to the commercialization of university research results. As mentioned in the background of this study, there are some barriers to the commercialization of university research results including the lack of organizational culture and knowledge production process (Houshamand, 2004), training and information and infrastructural challenges (Ansari and Sanjabi, 2013), extra-organizational factors including government forces, economic forces, educational system, macro laws and regulations, technological advances, etc. (Jahed and Arasteh, 2013). In the current study, based on the viewpoint of faculty members practicing in the branches of Lorestan Islamic Azad University, some factors such as availability of technological tools out of university with an average of 3.75 , interest and pursuing of research managers with an average of 3.48 and availability of technological tools within university with an average of 3.41 have the greatest impact on the commercialization of scientific research results, respectively. So it seems that some relatively uniform and stabile factors are involved in commercializing the results of scientific research in Iran, but it is essential to consider the views of experts, academic scholar, and researchers in formulating strategic commercialization map, and this will not be achieved unless through targeted research to achieve the desired results.

\section{References}

Mozafari, A., Shamsi, F., (2011). Methods and approaches to the commercialization of academic research, case study: Tabriz University; Journal of Science and Technology Policy; Year 3; Issue 4

Ansari, M., T., Sankabi, M. R. An analysis of challenges to the commercialization of research from the perspective of the faculty members of Iranian agricultural faculties; Iranian Journal of Agricultural Economics and Development, Volume 44, Issue 4

Baqerinejad, J., (2001); the function of Entrepreneurship University in employment creation; Proceedings of the forty-fourth meeting of the heads of Iranian universities and scientific and research centers

Jahed, H. A., Arasteh, H. R., Ja'efari, P. (2011). Identify and explain the personal factors influencing the commercialization of research results: A Case Study of Islamic Azad University, Department of Science and Research; Scientific-Research Journal of Science 
and Technology Policy; Year 4, Issue 1

Jahed, H., A., Arasteh, H., R. (2013). The extra-organizational factors influencing the commercialization of research results; Journal of Research and Planning in Higher Education; Issue 67

Khorshidi, Gh. H., (2004); Introduction to the Economics of Higher Education; Tehran: Ministry of Science, Research and Technology, Social and Cultural Affairs Deputyship, the Office of Social Planning and Cultural Studies

Razavi, M. R. Emami, H., Valaei, N., (2013). A review of data and commercialization of research projects in Faculty of Pharmacy, Beheshti University of Medical Sciences; 2001, 2011;, Journal of Medicine; Volume 37, Issue 4

Saeidikia, M., (2007). Basics and fundamentals of entrepreneurship; Tehran: Kia

Saljoughi, Kh. (2007). Science and technology parks and centers; ninth regional seminar of trilateral cooperation of government, industry, and Shahr Rai University

Alam Beigi, A. and et al; (2012). The role of commercialization of research on technological research and development of entrepreneurship in the agricultural sector of Iran; Iranian Journal of Agricultural Economics and Development; Volume 2-43, Issue 1

Faiouzat, Y. (2013). The role of university in national development; Tehran: Arasbaran

Me'emarnejad, A. (2005). Knowledge-based economy: requirements, indicators, Iran's position, challenges and strategies, Journal of Economics and new experiences, Issue 1

Noubakht, M., B., (2007). The Role of Islamic Azad University in socio- economic development of Iran; Tehran: Office of the development of knowledge production affiliated to Islamic Azad University Research Deputyship

Houshmand, H., Mirafzal, S., Rezaeipour, J. (2014). A model for evaluation of knowledge management in knowledge-oriented organizations in University of Qom, Journal of Technology Development; Issue 38

Hashemnia, Sh., et al; (2009). Factors affecting the dedicated revenues obtained from academic research at the Iran's Industrial University; Journal of Research and Planning in Higher Education; Issue 52

Etzkowitz. H. (2003). Research groups as quasi-firm: the invention of the entrepreneurial university, Research policy, 32

Wright, M., Clarysse, B., Mustar P. and Lockett A., 2007; Academic Entrepreneurship in Europe; Edward Elgar, Cheltenham and Northampton; 172-3. 